\title{
Anabases
}

ANABASES Traditions et réceptions de l'Antiquité

$10 \mid 2009$

Varia

\section{Thomas HOBBES, Translations of Homer, 1. The Iliad;}

\section{The Odyssey}

\section{Germaine Aujac}

\section{(2) OpenEdition}

\section{Journals}

Édition électronique

URL : http://journals.openedition.org/anabases/732

DOI : 10.4000/anabases.732

ISSN : 2256-9421

\section{Éditeur}

E.R.A.S.M.E.

\section{Édition imprimée}

Date de publication : 1 octobre 2009

Pagination : 293-295

ISSN : 1774-4296

\section{Référence électronique}

Germaine Aujac, «Thomas hоввEs, Translations of Homer, 1. The lliad; 2. The Odyssey », Anabases [En ligne], 10 | 2009, mis en ligne le 01 juillet 2011, consulté le 21 septembre 2020. URL : http:// journals.openedition.org/anabases/732 ; DOI : https://doi.org/10.4000/anabases.732

Ce document a été généré automatiquement le 21 septembre 2020.

(c) Anabases 


\title{
Thomas HOBBES, Translations of Homer, 1. The Iliad ; 2.The Odyssey
}

\author{
Germaine Aujac
}

\section{RÉFÉRENCE}

Thomas новвES, Translations of Homer, 1. The Iliad ; 2.The Odyssey, edited by Eric Nelson, Oxford, Clarendon Press, The Clarendon edition of the works of Thomas Hobbes, XXIV-

XXV, 2008, $848 \mathrm{p}$.

125 livres (relié) / ISBN 978-0-19-954100-3 ; 978-0-19-926214-4.

1 Le philosophe anglais Thomas Hobbes (1588-1679) vécut dans une époque troublée. Après le long règne d'Élisabeth ${ }^{\text {re }}$ (1558-1603), les Stuarts avaient pris le pouvoir (1603-1648), mais les conflits entre Charles $\mathrm{I}^{\mathrm{er}}$ et le Parlement finirent par provoquer une guerre civile qui se termina par l'exécution du roi en 1649 , et la proclamation de la République (1649-1660), avec Cromwell comme Lord protecteur (1653-1658). En 1660, la royauté était rétablie au profit de Charles II Stuart (1620-1685). Beau sujet de méditation pour un philosophe qui était aussi un scientifique confirmé, tout nourri de culture gréco-latine.

2 Après de solides études à Oxford, Hobbes visita l'Italie, y rencontrant Galilée. Devant la tournure inquiétante que prenaient les événements en Angleterre, il choisit de quitter son pays et passa en France douze années (1640-1651), fréquentant le cercle du Père Mersenne et le milieu des émigrés anglais (il donna des leçons de mathématiques au futur Charles II). Il y composa un De Cive (1642 en latin), et le fameux Léviathan (1651 en anglais) qui assura sa réputation de philosophe politique. De retour en Angleterre en 1651, il se soumit au nouveau pouvoir ; mais, bientôt accusé d'impiété, il lui fut interdit de rien publier ultérieurement qui puisse paraître subversif. Cela ne l'empêcha pas de rédiger un De Corpore (1655 en latin ; 1656 en anglais), un De homine (1658 en latin) et un Léviathan en latin (1668), ainsi que de nombreux traités scientifiques, notamment sur la quadrature du cercle. 
3 En 1629, il avait traduit en anglais La Guerre du Péloponnèse de Thucydide, mais c'est vers la fin de sa vie qu'il entreprit cette traduction des Poèmes d'Homère qui fait l'objet de l'édition procurée par Eric Nelson, dont la famille était arrivée aux États-Unis sur un bateau appelé Leviathan. L'introduction générale (p. XII-LXXVI) montre tout d'abord, exemples à l'appui, comment Hobbes, tout en traduisant assez exactement le texte d'Homère, se permet des excursus de sa composition sur les thèmes qui lui sont chers : il ajoute par exemple, à Odyssée, XI, 359-361, une réflexion de son crû, que les rois sont plus facilement obéis quand leurs caisses sont pleines. E. N. rappelle les circonstances de composition et les sources de ces traductions, faites à 87 ans pour l'Odyssée, à 88 ans pour l'Iliade. En fait, dès 1673, Hobbes avait publié Les voyages d'Ulysse, tels qu'il les raconte à Alcinous, roi de Phéacie (chant IX à XII), qui furent bien accueillis par le public, ce qui l'encouragea à donner la traduction complète des deux poèmes.

(a) Étienne (2 vol., Genève, 1566). Mais il s'est certainement inspiré également des Commentaires d'Eustathe aux ceuvres d'Homère, édités à Rome par A. Blado entre 1542 et 1550 (3 vol.). Déjà en 1581, l'anglais Arthur Hall avait publié une traduction des Dix livres de l'Iliade d'Homère, qui se fondait non sur le texte grec mais sur une traduction française de ces dix chants, procurée par Hugues Salel (1545). Quant à Georges Chapman, qui traduisit en anglais l'Iliade (1611), puis l'Odyssée (1616), il a certainement été bien connu de Hobbes. Ce dernier vante à l'occasion la traduction des poèmes d'Homère procurée par John Ogilby (Londres, 1660 et 1665), qu'il appelle son ami.

5 Faut-il s'étonner qu'un philosophe si important ait consacré les dernières années de sa vie à ces traductions de grec en anglais? On sait qu'il était interdit de publication sur tout sujet philosophique ou politique depuis 1665 . Aussi n'avait-il «rien d'autre à faire ", comme il le déclarait lui-même à la fin de l'adresse au lecteur qui sert de préface à sa traduction de l'Iliade. Mais il faut se garder de prendre cette déclaration au pied de la lettre. En fait Hobbes était persuadé que l'étude des classiques pouvait être tenue pour largement responsable de l'éclosion de la guerre civile, et qu'Homère en particulier pouvait être d'une lecture dangereuse, d'où son désir, sous prétexte de traduction, d'aligner l'Iliade et l'odyssée sur ses propres vues concernant la politique, la rhétorique, l'esthétique et la théologie. "L'Iliade et l'Odyssée d'Homère de Hobbes sont la continuation du Léviathan par d'autres moyens" déclare E.N. (p. XXII). C'est ce qui explique les multiples interventions du traducteur, que l'éditeur relève avec soin dans ses annotations.

6 Hobbes avait choisi de traduire les hexamètres d'Homère (qui comptent dans les 12 à 17 syllabes et ne comportent pas de rimes) en vers de dix syllabes, avec des rimes alternées. D'où la nécessité de raccourcir le texte grec, par exemple par la suppression d'adjectifs, et de se plier aux contraintes de la rime. Les modifications volontaires et les excursus pouvaient plus facilement se dissimuler sous l'apparente fluidité du discours. L'adresse au lecteur porte en effet sur les « vertus » d'un poème héroïque. Elles peuvent se résumer toutes dans la seule Discretion. Cette soi-disant « discrétion » consiste en ce que chaque partie du poème contribue à la fin qui lui est assignée, et à l'intention du Poète. «Et l'intention n'est pas seulement d'être utile, mais aussi de donner du plaisir au lecteur " (p. XCII). L'utilité recherchée n'est pas acquisition des richesses, pour le Poète ou pour le lecteur, mais accès «à la prudence, à la justice, et au courage, par l'exemple des grands et nobles personnages qu'Homère fait parler ou dont il décrit les actions » (ibid.). 
7 La communauté scientifique ne peut que rendre grâces à Eric Nelson d'avoir ainsi mis à sa disposition l'œuvre, si curieuse par ses multiples aspects mais si séduisante, de celui qui fut l'un des philosophes les plus originaux de son temps.

\section{AUTEURS}

GERMAINE AUJAC

Université de Toulouse (UTM)

aujac.germaine@wanadoo.fr 